\title{
Lifetime Prevalence of Psychiatric Disorders in City of Mosul-Iraq
}

\author{
Ahmad Meshaal ${ }^{1, *}$ Radhwan Hussein Ibrahim ${ }^{2}$ \\ ${ }^{1}$ M. Sc University of Mosul, College of Nursing, Mosul, Iraq) \\ ${ }^{2}$ PhD., Professor, University of Mosul, College of Nursing, Mosul, Iraq \\ ${ }^{*}$ Corresponding author.Email: ahmadsf05@uomosul.edu.iq
}

\begin{abstract}
Introduction: To calculate the prevalence of mental disorders and identify the availability of essential psychotropic medicines and mental health facilities in the hospitals of Mosul city Methods: A retrospective study was conducted in city of Mosul_Iraq for the period between January 12020 to January 12021 . The medical records were reviewed in three main hospitals in Mosul city and interview with the chief of the mental health department for each hospital to data collection. Results: A total of (17022) mental disorder cases registered in the Mosul hospitals (52\%) were females and (48\%) were males. Most patients were reported in the age group of 20-44 years. The mental disorder was more between females than males in 19-40 years, but in 27-59 years, males were more., most of them were anxiety disorders. Behavioural conditions because of substance use were more between males but anxiety, mood disorders, schizophrenic diseases, neurotic, and stress-related disorders, and more between females. Conclusion: Anxiety disorder was the most occurred mental disorder, followed by mood disorders due to disorders conflicts that happened in the city. Counselling can be helpful to for avoiding most mental disorders.
\end{abstract}

Keywords: mental disorder, Age, anxiety disorder, Psychotropic drugs.

\section{INTRODUCTION}

Wars leave many effects that are more complex and deeper than we can imagine, beyond being physical or organic effects and extending to psychological and mental consequences that may remain and develop for many years even after wounds heal and disappear. [1-3] It is not strange with what our Arab world, Iraqi society, and more specifically the City of Mosul, is going through in recent decades and mental disorders in thousands of people. [4, 5] The World Health Organization (WHO) estimates that one in five individuals in conflict zones suffer from depression, anxiety, posttraumatic stress disorder, bipolar disorder, or schizophrenia. $[6,7]$ These findings show the long-term effects of war-related conflicts, such as in Afghanistan, Iraq, South Sudan, Syria, and Yemen, and that the degree of mental diseases is far higher in wartime than in peacetime. [8-10] The governorate of Nineveh is located in northern Iraq. The city of Mosul is about 465 kilometres $(290 \mathrm{mi}$ ) from the capital city, Baghdad. (Ibrahim, 2018: 158). The Nineveh
Governorate is populated by just under three and a half million people, half of whom live in Mosul. ISIS took control of Mosul on June 4, 2014, for 29 months, during which people witnessed difficult events and deteriorating economic conditions that affected the psychological and social state of the people in the city. The process of liberating the city left behind victims and massive destruction of infrastructure and health institutions. Psychological conditions worsened, and there was an apparent increase in suicide rates. The research on mental health in Iraq is minimal. There is only one available survey on mental health in Iraq, which shows the prevalence for anxiety disorders and major depressive disorder is between thirteen percent and nine percent, respectively, with major depressive disorder as the more prevalent group (7.2 percent). It is important to have a good analysis of the current health situation in our policies, strategies and plans to be created and updated. A strong analysis must have a thorough understanding of the patient's social and environmental influences on the illness. Instead of studying only one old disease, it is 
more important to study all possible health problems in the future. In many countries, there is a global imbalance in access to and provision of mental health care. The mental health care provided in all nations is in short supply, meaning even with some of the access to people, $50 \%$ of people are without needed mental health care. Mental health has become a significant concern to be addressed by the community. The investment in delivering mental health care in developing nations has led to new mental health approaches in these countries. The press needs to better understand how to implement, and scale-up mental health services are growing as evidence shows successful treatment for severe disorders.

\section{METHODS}

Study design and procedure: The current study adopted an analytical study design to accomplish the objectives of the study for the period from September 1, 2019, until 1th April 2020.

\subsection{Study participants and sampling}

Data collected from the main private clinics of two sides of Mosul. The study was carried out in three teaching hospitals in Mosul city, which is located in the north of Iraq. The hospitals are Al-Salam hospital, Mosul general hospital, and Ibn- Sina hospital. And also, from all health centres in the districts and suburbs of Nineveh Governorate, through the data available in the Public Health Department / Non-Communicable Diseases Division. All these hospitals and health centres are in Nineveh Governorate, and they offer their services to Nineveh city and nearby cities. The collection of data was done in the period between November 162019 and February 282020.

\subsection{Study instruments and measures}

Key informant interviews were conducted as part of the situation analysis. The instrument of the study is "WHO Assessment Instrument for Mental Health Systems (WHO-AIMS)" was composed of general information and (5) sections, which included According to the "World Health Organization Assessment Instrument for Mental health Systems (WHO-AIMS)" is a WHO tool for collecting essential information on the mental health system of a country or region.

\subsection{Ethical aspects}

Formal approval was obtained to conduct the study from the Nursing College at the University of Mosul and the Ethical Research Committee in the Nineveh Health Directorate. The researcher took a written consent from Mental health institutions officials for data collection, then explained all the objectives and procedures to the person responsible of the institution.

\subsection{Data analysis}

Data analysis was done by Statistical Package for Social Sciences (S.P.S.S.) version 26. A descriptive approach was applied. Mean \pm S.D., median (range), or frequency

(percentage) were computed.

\section{TABLES}

This table shows the percentage of mental illnesses recorded in the health records for 2020 and shows the distribution of ages and gender for each disorder in Nineveh governorate.

Table 1. Percentage of mental disorders with age and gender in Nineveh

\begin{tabular}{|c|c|c|c|c|c|c|c|}
\hline age & gender & anxiety & $\begin{array}{c}\text { Mood } \\
\text { disorders }\end{array}$ & $\begin{array}{l}\text { Developmental } \\
\text { disorders }\end{array}$ & psychosis & $\begin{array}{c}\text { Neurotic and } \\
\text { stress- } \\
\text { related }\end{array}$ & $\begin{array}{c}\text { alcohol and } \\
\text { substance } \\
\text { abuse }\end{array}$ \\
\hline \multirow{2}{*}{$<1$ year } & $\mathrm{M}$ & $0.00 \%$ & $0.00 \%$ & $0.00 \%$ & $0.00 \%$ & $0.00 \%$ & $0.00 \%$ \\
\hline & $\mathrm{F}$ & $0.00 \%$ & $0.00 \%$ & $0.00 \%$ & $0.00 \%$ & $0.00 \%$ & $0.00 \%$ \\
\hline \multirow{2}{*}{$1-4$} & $\mathrm{M}$ & $0.00 \%$ & $0.00 \%$ & $0.06 \%$ & $0.00 \%$ & $0.00 \%$ & $0.00 \%$ \\
\hline & $\mathrm{F}$ & $0.00 \%$ & $0.00 \%$ & $0.08 \%$ & $0.00 \%$ & $0.00 \%$ & $0.00 \%$ \\
\hline \multirow{2}{*}{$5-9$} & $\mathrm{M}$ & $1.47 \%$ & $0.02 \%$ & $1.29 \%$ & $0.01 \%$ & $0.00 \%$ & $0.00 \%$ \\
\hline & $\mathrm{F}$ & $0.76 \%$ & $0.02 \%$ & $1.52 \%$ & $0.01 \%$ & $0.00 \%$ & $0.00 \%$ \\
\hline \multirow{2}{*}{$10-14$} & $\mathrm{M}$ & $2.16 \%$ & $0.08 \%$ & $1.93 \%$ & $0.03 \%$ & $0.02 \%$ & $0.02 \%$ \\
\hline & $\mathrm{F}$ & $2.73 \%$ & $0.14 \%$ & $1.64 \%$ & $0.05 \%$ & $0.01 \%$ & $0.01 \%$ \\
\hline \multirow{2}{*}{$15-19$} & $\mathrm{M}$ & $4.29 \%$ & $2.02 \%$ & $1.34 \%$ & $0.99 \%$ & $2.26 \%$ & $0.05 \%$ \\
\hline & $\mathrm{F}$ & $4.98 \%$ & $2.52 \%$ & $1.22 \%$ & $1.89 \%$ & $2.58 \%$ & $0.04 \%$ \\
\hline \multirow{2}{*}{$20-44$} & $\mathrm{M}$ & $7.62 \%$ & $5.19 \%$ & $1.31 \%$ & $3.13 \%$ & $1.78 \%$ & $0.25 \%$ \\
\hline & $\mathrm{F}$ & $7.00 \%$ & $3.90 \%$ & $0.98 \%$ & $2.35 \%$ & $1.85 \%$ & $0.06 \%$ \\
\hline \multirow{2}{*}{$45-65$} & $\mathrm{M}$ & $2.06 \%$ & $3.67 \%$ & $0.94 \%$ & $2.04 \%$ & $1.53 \%$ & $0.10 \%$ \\
\hline & $\mathrm{F}$ & $3.60 \%$ & $2.61 \%$ & $0.48 \%$ & $3.27 \%$ & $1.67 \%$ & $0.06 \%$ \\
\hline \multirow{2}{*}{$>65$} & $\mathrm{M}$ & $1.68 \%$ & $0.09 \%$ & $0.64 \%$ & $0.33 \%$ & $0.00 \%$ & $0.00 \%$ \\
\hline & $\mathrm{F}$ & $0.96 \%$ & $0.40 \%$ & $0.57 \%$ & $0.23 \%$ & $0.00 \%$ & $0.00 \%$ \\
\hline \multicolumn{2}{|c|}{ Total } & $39.31 \%$ & $20.66 \%$ & $14.00 \%$ & $14.33 \%$ & $11.70 \%$ & $0.59 \%$ \\
\hline
\end{tabular}


Table 2. Human resources Distribution of human recourses according to their locations in mental health centers.

\begin{tabular}{|c|c|c|c|c|c|c|}
\hline CATEGORY & $\begin{array}{l}\text { IBN- } \\
\text { SINA }\end{array}$ & $\begin{array}{l}\text { AL- } \\
\text { SALAM }\end{array}$ & $\begin{array}{c}\text { AL } \\
\text { MOUSEL } \\
\text { GEN. }\end{array}$ & \multicolumn{2}{|c|}{ QUALIFICATION } & Total \\
\hline $\begin{array}{c}\text { Psychiatrists } \\
\text { General } \\
\text { practitioner (GP) }\end{array}$ & $\begin{array}{l}6 \\
1\end{array}$ & $\begin{array}{l}3 \\
3\end{array}$ & $\begin{array}{l}1 \\
2\end{array}$ & \multicolumn{2}{|c|}{$\begin{array}{c}\text { P.H.D } \\
\text { BACHELOR }\end{array}$} & 16 \\
\hline $\begin{array}{l}\text { Other Medical } \\
\text { Doctors, Not } \\
\text { Specialized in } \\
\text { Psychiatry } \\
\end{array}$ & 5 & 1 & 1 & \multicolumn{2}{|c|}{ BACHELOR } & 7 \\
\hline Nurses & 4 & 1 & 1 & \multicolumn{2}{|c|}{$\begin{array}{l}\text { MASTER } \\
\text { BACHELOR }\end{array}$} & 6 \\
\hline Psychologists & 7 & 2 & 2 & \multicolumn{2}{|c|}{ BACHELOR } & 11 \\
\hline $\begin{array}{l}\text { Mental Health } \\
\text { Social Workers }\end{array}$ & 2 & 6 & 2 & \multicolumn{2}{|c|}{ BACHELOR } & 10 \\
\hline Support Staff & 8 & 2 & 3 & & & 13 \\
\hline \multicolumn{2}{|c|}{ N/AREA } & 33 & 18 & 12 & 63 & \\
\hline \multicolumn{2}{|c|}{$\% / A R E A$} & $52.38 \%$ & $28.57 \%$ & $19.04 \%$ & $100 \%$ & \\
\hline
\end{tabular}

Table 3. Availability of Essential Psychotropic Medicines in Mosul hospitals.

\begin{tabular}{|l|c|c|c|}
\hline CATEGORY & $\begin{array}{c}\text { IBN-SINA } \\
\text { hospital }\end{array}$ & $\begin{array}{c}\text { AL-SALAM } \\
\text { Hospital }\end{array}$ & $\begin{array}{c}\text { AL MOUSEL GEN. } \\
\text { hospital }\end{array}$ \\
\hline Amiptriptyline Tablets 25mg & $\checkmark$ & $X$ & $\checkmark$ \\
\hline Chlorpromazine Injection 50mg/2ml & $X$ & $X$ & $X$ \\
\hline Chlorpromazine HCl Tablets $25 \mathrm{~m}$ & $\mathrm{X}$ & $\mathrm{X}$ & $\checkmark$ \\
\hline Diazepam Injection 10mg & $\checkmark$ & $\mathrm{X}$ & $\checkmark$ \\
\hline Haloperidol Injection 5mg/amp & $\checkmark$ & $\mathrm{X}$ & $\mathrm{X}$ \\
\hline Haloperidol Tablets 5mg & $\checkmark$ & $\checkmark$ & $\checkmark$ \\
\hline Phenobarbitone Tablets 15mg & & $\mathrm{X}$ & $\mathrm{X}$ \\
\hline Phenytoin Sodium Tablets 100mg & $\mathrm{X}$ & $\mathrm{X}$ & $\mathrm{X}$ \\
\hline Promethazine HCl Injection 50mg/2ml & $\mathrm{X}$ & $\mathrm{X}$ & $\mathrm{X}$ \\
\hline Benzhexol Tablets 5mg & $\mathrm{X}$ & $\checkmark$ & $\checkmark$ \\
\hline Syringes 5ml + Needles & $\checkmark$ & & \multicolumn{2}{|c|}{} \\
\hline
\end{tabular}

Table 4. Types of mental health facilities according to services provided in Mosul city.

\begin{tabular}{lc}
\hline SERVICES & NUMBERS \\
\hline Outpatient Care & 7 \\
Inpatient Care & 1 \\
Outreach Activities (by Hospital Staff) & 0 \\
Preventive / Promotive Services & 5 \\
In-Service Training & 3 \\
Supervision & 3 \\
Health Information System & 7 \\
Drug Supply System & 3 \\
\hline
\end{tabular}




\section{DISCUSSION}

The details recorded here document a high lifetime prevalence of mental conditions in the City of Mosul, with $(26.6 \%)$ of respondents reporting a lifetime history of at least one of the DSMIV/ICD-10 disorders considered in the study. This is not as big an "estimate" of incidence as in the U.S.A., where one out of every two Americans is afflicted by one or more DSM-IV/ICD-10 disorders [11]. It is, however, slightly higher than the estimation of a recent Yoruba-speaking Nigerian report and higher than in the number of other nations participating in the first phase of the World Mental Health Survey Program of the WHO.[12-14] Examining socio-demographic conditions helps to explain the origins and occurrence of different mental illnesses. Gender roles and norms are linked to emotional and mental stability in most, if not all, countries. However, it is worth noting that Caucasians and Asians showed similar rates of lifetime prevalence and Age of onset of psychiatric disorders. Unlike other Western countries' religious communities, the quality of substance and alcohol use disorders in the Iraqi population is much lower. This community includes many Muslims, and the influence of moderate alcohol intake may be the explanation behind this data.[15-19].Instead of examining the prevalence rates, looking at the specific Age of onset rates across different cohorts or "the number of onsets within a specific period" provides another approach to seeing the meaning of the prevalence rates found here. The estimates for significant anxiety varied among cohorts of participants in the survey. The research results suggest that adult socialization is essential for developing posttraumatic disorder (P.T.S.D.), G.A.D., and M.D.D. over time. The evaluation highlighted the high prevalence rate (39.32\%) and early Age of onset (17 years). It is much more evident in the more recent cohort, indicating a novel problem. In several other countries, the increasing prevalence of substance use disorders was found in successive cohorts; However, in earlier cohorts than seen, the increase was generally found to start. During the rise of ISIS in Mosul, people lost all contact with the outside world. There was no media or phones or internet so people couldn't have a connection with the outside world. This caused the people of Mosul to have multiple mental disorders from the rise of ISIS. These results compared with those of other studies by the World Health Organization (2012); it is evident that the prevalence of mental disorders in Iraq is higher compared with most mental disorders in Iran[20- 23], Ukraine[24, 25], and the United States[26]. It was found that the majority of mental disorders in Mosul City increased between 1999 and 2010. This fact would not necessarily indicate an increase in the number of people suffering from mental illnesses, but it may signify an increase in the number of people on medications for mental health conditions. In the Iraq Mental Health Survey (I.M.H.S.)[27], the prevalence and correlates of DSM-IV disorders of the 12-month incidence is $13.6 \%$, with $42.1 \%$ of cases classified as mild, $36.0 \%$ of cases classified as moderate, and $21.9 \%$ of patients classified as severe. Bipolar depression is the most likely to be serious ( 76.9 percent), accompanied by substance-related conditions (54.9 percent), major depressive disorder (39.1 percent), and a few anxiety disorders. (32.3-38.2 percent for panic disorder, G.A.D., social phobia, agoraphobia, and P.T.S.D.). Instead, a limited number of phobias and misbehaviors are graded as extreme. $3.0 \%$ in the sample, although just $1.5 \%$ are diagnosed as possessing psychiatric illness. The most prevalent condition is Major Depressive Disorder, which is accompanied by Generalized Anxiety Disorder and Specific Phobia (I.E.D.). There is a higher incidence of psychological disorders in females than males, which is compatible with other studies conducted in Iraq. As possible reasons for a parental conflict, gender and marital roles can be considered. Our research shows that the effects on the mental health of work at home are much worse. It is likely due to biological or social factors more likely to women than to men that Iraqi women are more likely to develop mental disorders than Western cultures. [28-30].The findings showed a substantial connection between Age and mental illness. Statistics indicate a rise in the Age of patients with the condition. Physical and psychological wellbeing can be linked to decreased exercise and increased susceptibility to depression and illness in older adults. The present study finding reveals that people

aged (20-44) years is more than the result with studies performed in Iran, which indicate higher rates of people aged 18 to 24 years[31]. Just three outpatient mental health services in the city are available. These clinics treated hospital patients about 900/100,000. Of patients treated in mental health outpatient facilities, $60 \%$ are female, and $25 \%$ are children or adolescents. Most of the clients were diagnosed with neurotic, stress-related, and somatoform disorders and mood and affective disorders $(11.7 \%)(20.6 \%)$. Patients are usually among 50-80\% who receive psychosocial interventions. All mental health outpatient facilities have a shortage of mental health medications all year round. There is no national mental health authority to provide guidelines and recommendations to the local government for mental health. Mental health services in rural areas are inadequate; there is only one functioning mental health hall in the entire region managed by the Ministry of Health. Unfortunately, a hospital that ISIS bombed during the liberation operation was reduced to rubble.

\section{CONCLUSION}

anxiety disorder was the most occurred mental disorder, followed by mood disorders due to conditions and 
conflicts in the city. Counseling can be helpful to for avoiding most mental disorders. Enhance mental health care facilities and human resources will be the resolution for managing mental illnesses.

\section{ACKNOWLEDGMENTS}

We would like to thank the authorities who granted permission for this study and all the participants who support us.

\section{REFERENCES}

[1] Miller, K.E., A.J.S.s. Rasmussen, and medicine, War exposure, daily stressors, and mental health in conflict and post-conflict settings: bridging the divide between trauma-focused and psychosocial frameworks. 2010. 70(1): p. 7-16.

[2] Scholte, W.F., et al., Mental health symptoms following war and repression in eastern Afghanistan. 2004. 292(5): p. 585-593.

[3] Devakumar, D., et al., The intergenerational effects of war on the health of children. 2014. 12(1): p. 1-15.

[4] Al-Nuaimi, M.A., R.A. Hamad, and R.K.J.Q.m.j. Lafta, Effects of witnessing or exposure to community violence on mental health of Iraqi men. 2015. 2015(1): p. 10.

[5] Niaz, U.J.A.J.o.P., Psychiatric Impact of Wars and Terrorism on Muslim Women. 2014. 25(1).

[6] Organization, W.H., The World Health Report 2001: Mental health: new understanding, new hope. 2001.

[7] Patel, V.J.B.m.b., Mental health in low-and middleincome countries. 2007. 81(1): p. 81-96.

[8] Kadir, A., S. Shenoda, and J.J.P.o. Goldhagen, Effects of armed conflict on child health and development: a systematic review. 2019. 14(1): p. e0210071.

[9] Lackner, H., Yemen in Crisis: Road to war. 2019: Verso Books.

[10] Garry, S. and F.J.J.o.P.H. Checchi, Armed conflict and public health: into the 21 st century.

[11] Ekselius, L., et al., Personality disorders in the general population: DSM-IV and ICD-10 defined prevalence as related to sociodemographic profile. 2001. 30(2): p. 311-320.

[12] Ojagbemi, A., et al., The Independent Association of Prestroke Psychiatric Symptoms and Acute Phase Delirium with Poststroke Mortality at One Year in Nigeria. 2021. 30(4): p. 105622.
[13] Amoo, G., et al., Prevalence and pattern of psychiatric morbidity among community-dwelling elderly populations in Abeokuta, Nigeria. 2020. 33(6): p. 353-362.

[14] Ojagbemi, A., T. Bello, and O.J.I.J.o.G.P. Gureje, The roles of depression and social relationships in the onset and course of loneliness amongst Nigerian elders. 2020.

[15] Le, T.H., et al., Alcohol use and misuse: Perspectives from seldom heard voices, in The Handbook of Alcohol Use. 2021, Elsevier. p. 453481.

[16] Danquah Obeng-Dwamena, A., Alcohol Use and Mental Health in Ghana. 2020, University of Ghana.

[17] Johnson, P.L., Trauma and Mental Health Symptoms among Clients in Residential Treatment for Substance Use Disorders. 2020, Ohio University.

[18] Maccombs, S.R., Exploring Psychological Distress and Impulsivity as Predictors of Problematic Alcohol or Drug Use among Undergraduate College Students. 2020, Ohio University.

[19] Mkhitarian, L.A., The relationship of legal history to mood and substance abuse symptoms among homeless men and women in a residential recovery program. 2020.

[20] Mirghaed, M.T., H.A. Gorji, and S.J.I.j.o.p.m. Panahi, Prevalence of psychiatric disorders in Iran: A systematic review and meta-analysis. 2020. 11.

[21] NOORBALA, A.A., B. D.A.M.A.R.I., and I.S. R.I.A.Z.I., Evaluation of mental disorders incidence trend in Iran. 2014.

[22] Noorbala, A.A., et al., Mental health survey of the adult population in Iran. 2004. 184(1): p.

[23] Noorbala, A.A. and S.J.A.I.M. Akhondzadeh, Mental health study process into prevalence of mental disorders in iran. 2015. 18(2): p. 74-5.

[24] Bromet, E.J., et al., Epidemiology of psychiatric and alcohol disorders in Ukraine. 2005. 40(9): p. 681690.

[25] Deswal, B.S., A.J.I.j.o.c.m.o.p.o.I.A.o.P. Pawar, and S. Medicine, An epidemiological study of mental disorders at Pune, Maharashtra. 2012. 37(2): p. 116.

[26] Hossain, M.M., et al., Prevalence of mental disorders among people who are homeless: An umbrella review. 2020. 66(6): p. 528-541.

[27] Alhasnawi, S., et al., The prevalence and correlates of DSM-IV disorders in the Iraq Mental Health Survey (I.M.H.S.). 2009. 8(2): p. 97. 
[28] Norbury, C.F. and A.J.D.p. Sparks, Difference or disorder? Cultural issues in understanding neurodevelopmental disorders. 2013. 49(1): p. 45.

[29] De Vaus, J., et al., Exploring the East-West divide in prevalence of affective disorder: A case for cultural differences in coping with negative emotion. 2018. 22(3): p. 285-304.

[30] Viswanath, B. and S.K.J.I.J.o.P.M. Chaturvedi, Cultural aspects of major mental disorders: a critical review from an Indian perspective. 2012. 34(4): p. 306-312.

[31] Noorbala, A., et al., A view of mental health in Iran. 2001. 